\title{
Editorial: Functional Metal-Organic Frameworks: Gas Sorption, Separation, and Heterogeneous Catalysis
}

\author{
Seong Huh ${ }^{1 *}$, Youngmee Kim ${ }^{2 *}$, Jian Lü ${ }^{3 *}$, Krunoslav Užarević ${ }^{4 *}$ and Yong Yan ${ }^{5 *}$ \\ ${ }^{1}$ Department of Chemistry, Hankuk University of Foreign Studies Seoul, Seoul, South Korea, ${ }^{2}$ Department of Chemistry and \\ Nanoscience, Ewha Womans University, Seoul, South Korea, ${ }^{3}$ College of Resources and Environment, Fujian Agriculture and \\ Forestry University, Fuzhou, China, ${ }^{4}$ Division of Physical Chemistry, Ruder Bošković Institute, Zagreb, Croatia, ${ }^{5}$ Department \\ of Chemistry, University of Liverpool, Liverpool, United Kingdom
}

Keywords: metal-organic frameworks (MOFs), catalysis, defected MOFs, Co-MOF-74 CPO-27-Co, gas sorption, thermochromic MOFs, POM@MOF composites, polyoxometalate MOF

\section{Editorial on the Research Topic}

\section{OPEN ACCESS}

Edited and reviewed by: Jie-Sheng Chen,

Shanghai Jiao Tong University, China

${ }^{*}$ Correspondence:

Seong Huh

shuh@hufs.ac.kr

Youngmee Kim

ymeekim@ewha.ac.kr

Jian Lü

jian_lu_fafu@163.com

Krunoslav Užarevic

krunoslav.uzarevic@irb.hr

Yong Yan

yong.yan@liverpool.ac.uk

Specialty section:

This article was submitted to Colloidal Materials and Interfaces,

a section of the journal

Frontiers in Materials

Received: 12 November 2019 Accepted: 28 November 2019

Published: 10 December 2019

Citation:

Huh S, Kim Y, Lü J, Užarević K and Yan Y (2019) Editorial: Functional Metal-Organic Frameworks: Gas

Sorption, Separation, and Heterogeneous Catalysis.

Front. Mater. 6:326.

doi: 10.3389/fmats.2019.00326 $\begin{aligned} & \text { Functional Metal-Organic Frameworks: Gas Sorption, Separation, and } \\ & \text { Heterogeneous Catalysis }\end{aligned}$
a

Metal-organic frameworks (MOFs), or porous coordination polymers (PCPs), are a class of widely investigated porous materials (Li et al., 1999; Férey, 2008; Yuan et al., 2018). The combination of the rich coordination chemistry of metal centers and varied geometry of organic linkers has led to unprecedented structural versatility and tunability, which is also reflected in their chemical and physical properties. Today, MOFs are studied particularly for their potential application in storage (Ma and Zhou, 2010; Li et al., 2019), separation (Lin et al., 2019), water harvesting (Kalmutzki et al., 2018), harmful waste remediation (Bobbitt et al., 2017), catalysis (Zhu et al., 2017), batteries development (Baumann et al., 2019), electronics (Stavila et al., 2014), drug delivery (Stavila et al., 2014), and more (Tuffnell et al., 2019). Also, MOFs attracted significant attention for their dynamic properties (Coudert, 2015). such as well-demonstrated structural flexibility and ability to respond to external stimuli, leading to new and exciting properties such as negative linear compressibility and negative Poisson ratio. With a continually rising number of studies and publications, materials based on MOFs have now matured to be seriously considered for broad applications, and a growing number of MOFs is now commercially available. IUPAC, the International Union of Pure and Applied Chemistry, has enlisted MOFs into their list of 10 chemistry innovations and technologies that may change the world (Gomollón-Bel, 2019).

Here, we are proud to present the Research Topic "Functional Metal-Organic Frameworks: Gas Sorption, Separation, and Heterogeneous Catalysis," which contains contemporary studies on MOFs, their properties, and potential applications. This Research Topic is comprised of four original research papers from seven different institutions. The work by Prof. Emmerling from BAM Institute in Berlin and colleagues (Villajos et al.) describes a new synthetic approach by partial linker substitution, which results in defected phases of a prototypical cobalt MOF, Co-MOF-74. The authors were mainly focused on the assessment of the stability of these new MOFs and the availability of the free coordination sites of cobalt phases. This study also shows how the introduced defects enable the more facile diffusion of gaseous guests, which can have a substantial impact on their application in catalysis and storage. Choi et al., describes a new synthetic approach toward exciting indium MOF based on anionic [In(carboxylate)4]- nodes. The high-quality crystals for 
their study were obtained solely from the ionic-liquid solution. The authors studied the sorption of nitrogen, hydrogen, and carbon dioxide gases into their porous MOF, establishing facts about the porosity, cooperative binding, and the unusually high isosteric heat of hydrogen adsorption. Bommakanti and Das reports on new cobalt(II) MOF with bifunctional trigonal planar ligand based on 4,4'-bipyridine and carboxylic acid. This MOF displayed reversible thermochromic behavior, changing the color from orange to dark purple under elevated temperatures, which was directly correlated to the loss of coordinated solvent molecules and the change in the metal-node coordination sphere, leading to an amorphous material with tetrahedral cobalt(II) coordination. The contribution by Buru et al. is focused on encapsulation and the study of the influence of Keggin-type polyoxometalate (POM)movement on the catalytic properties of two zirconium MOFs. The authors show that both MOFs containing immobilized polyoxometalates exhibit a significant increase in catalytic activity when compared to MOFs or polyoxometalates alone. The authors also studied the activity

\section{REFERENCES}

Baumann, A. E., Burns, D. A., Liu, B., and Thoi, V. S. (2019). Metalorganic framework functionalization and design strategies for advanced electrochemical energy storage devices. Commun. Chem. 2, 86. doi: 10.1038/s42004-019-0184-6

Bobbitt, N. S., Mendonca, M. L., Howarth, A. J., Islamoglu, T., Hupp, J. T., Farha, O. K., et al. (2017). Metal-organic frameworks for the removal of toxic industrial chemicals and chemical warfare agents. Chem. Soc. Rev. 46, 3357-3385. doi: 10.1039/C7CS $00108 \mathrm{H}$

Coudert, F.-X. (2015). Responsive metal-organic frameworks and framework materials: under pressure, taking the heat, in the spotlight, with friends. Chem. Mater. 27, 1905-1916. doi: 10.1021/acs.chemmater.5 b00046

Férey, G. (2008). Hybrid porous solids: past, present, future. Chem. Soc. Rev. 37, 191-214. doi: 10.1039/B61 $8320 \mathrm{~B}$

Gomollón-Bel, F. (2019). Ten chemical innovations that will change our world: IUPAC identifies emerging technologies in chemistry with potential to make our planet more sustainable. Chem. Int. 41, 12-17. doi: 10.1515/ci-2019-0203

Kalmutzki, M. J., Diercks, C. S., and Yaghi, O. M. (2018). Metal-organic frameworks for water harvesting from air. Adv. Mater. 30:1704304. doi: 10.1002/adma.201704304

Li, H., Eddaoudi, M., O’Keeffe, M., and Yaghi, O. M. (1999). Design and synthesis of an exceptionally stable and highly porous metal-organic framework. Nature 402, 276-279. doi: 10.1038/46248

Li, H., Li, L., Lin, R.-B., Zhou, W., Zhang, Z., Xiang, S., et al. (2019). Porous metal-organic frameworks for gas storage and separation: status and challenges. Energy Chem. 1:100006. doi: 10.1016/j.enchem.2019.1 00006 trends in both POM@MOF materials and have established different behavior based on the location of POM and content of the pores, thus showing the importance of the location of the active site on the heterogeneous support that was the MOFs role in this particular composite material.

As scientists involved in the field, we are very excited about the articles in this Research Topic, showing new and nonconventional approaches toward these exciting materials, and indicating the fast and dynamic changes happening in this area of research. We hope the readers will find in these articles new and useful information for their research and come with new directions for further developments in the field of MOFs and MOF composites.

\section{AUTHOR CONTRIBUTIONS}

All authors listed have made a substantial, direct and intellectual contribution to the work, and approved it for publication.

Lin, R.-B., Xiang, S., Xing, H., Zhou, W., and Chen, B. (2019). Exploration of porous metal-organic frameworks for gas separation and purification. Coord. Chem. Rev. 378, 87-103. doi: 10.1016/j.ccr.2017.09.027

Ma, S., and Zhou, H.-C. (2010). Gas storage in porous metal-organic frameworks for clean energy applications. Chem. Commun. 46, 44-53. doi: 10.1039/B916295J

Stavila, V., Talin, A. A., and Allendorf, M. D. (2014). MOF-based electronic and opto-electronic devices. Chem. Soc. Rev. 43, 5994-6010. doi: 10.1039/C4CS00096J

Tuffnell, J. M., Ashling, C. W., Hou, J., Li, S., Longley, L., Ríos Gómez, M. L., et al. (2019). Novel metal-organic framework materials: blends, liquids, glasses and crystal-glass composites. Chem. Commun. 55, 8705-8715. doi: 10.1039/C9CC01468C

Yuan, S., Feng, L., Wang, K., Pang, J., Bosch, M., Lollar, C., et al. (2018). Stable metal-organic frameworks: design, synthesis, and applications. Adv. Mater. 30:1704303. doi: 10.1002/adma.201704303

Zhu, L., Liu, X.-Q., Jiang, H.-L., and Sun, L.-B. (2017). Metal-organic frameworks for heterogeneous basic catalysis. Chem. Rev. 117, 8129-8176. doi: 10.1021/acs.chemrev.7b00091

Conflict of Interest: The authors declare that the research was conducted in the absence of any commercial or financial relationships that could be construed as a potential conflict of interest.

Copyright (c) 2019 Huh, Kim, Lü, Užarević and Yan. This is an open-access article distributed under the terms of the Creative Commons Attribution License (CC BY). The use, distribution or reproduction in other forums is permitted, provided the original author(s) and the copyright owner(s) are credited and that the original publication in this journal is cited, in accordance with accepted academic practice. No use, distribution or reproduction is permitted which does not comply with these terms. 